Volney de M. Câmara 2

Maria Izabel de Freitas Filhote 2

Maria Imaculada Medina Lima 2

Flávio Valdozende Alheira 2

Márcio Santos Martins 2

Thor Oliveira Dantas 2

Ronir Raggio Luiz 2

\section{Metodologia para prevenir exposição ao mercúrio em adolescentes de garimpos de ouro em Mariana, Minas Gerais, Brasil 1}

\author{
Methodology to prevent mercury exposure \\ among adolescents from goldmine areas in \\ Mariana, state of Minas Gerais, Brazil 1
}

1 Projeto financiado com recursos da Organização Pan-Americana da Saúde (Programa de Saúde Ambiental da Representação no Brasil) e apoiado pela Secretaria de Estado de Saúde de Minas Gerais, Sub-Reitoria de Desenvolvimento e Extensão (UFRJ), e Fundação Universitária José Bonifácio, Universidade Federal do

Rio de Janeiro.

2 Núcleo de Estudos de Saúde Col etiva, Centro de Ciências da Saúde, Universidade Federal do Rio de Janeiro, Hospital Universitário Clementino Fraga Filho. Av. Brigadei ro Trompowsky s/no, 5o andar (Ala Sul) Rio de Janeiro, RJ, 21941-590, Brasil.
Abstract The main objective of this study was to promote the evaluation of an educational method to i dentify health risks among adolescents exposed to mercury by thei $r$ work in gold mining production. The project was carried out with adolescents from a public school from the District of Monsenhor Horta, Municipality of Mariana, state of Minas Gerais. Statistical evaluation of the results revealed a significant increase in the amount of correct answers between the first and fifth stage concerning the definition of work accidents and its importance in relation to work-related diseases, accidents on route to and from the work place and violence at work site itself.

Key words Mercury; Adol escents; Occupational Health; Environmental Health

Resumo O principal objetivo deste estudo foi promover a avaliação de uma metodologia educativa para identificar e refletir, criticamente, sobre os riscos à saúde de adolescentes causados pelo trabalho em garimpos de ouro. O projeto foi realizado com adol escentes que estudavam na Escola Estadual Cônego Braga do Distrito de Monsenhor Horta, Município de Mariana, Minas Gerais, Brasil. A avaliação dos resul tados através de testes estatísti cos revel ou um si gni fi cativo acréscimo de respostas corretas da primei ra para a última fase sobrea defini ção de aci dentes de trabal ho e sua equi paração com as doenças do trabal ho, os aci dentes de traj eto e as agressões no local de trabalho.

Palavras-chave Mercúrio; Adolescentes; Saúde do Trabalhador; Saúde Ambiental 


\section{Introdução}

A utilização de mercúrio em processos de produção de ouro no Brasil é um exemplo de poluição por resíduos perigosos que atinge populações ocupacionais e não-ocupacionais. $O$ processo produtivo do ouro causa a exposição direta dos trabalhadores ao mercúrio metálico nos ambientes de trabal ho e a exposição indireta de populações não-ocupacionais que estejam próximas às áreas garimpeiras. O mercúrio metálico pode também sofrer um processo de metilação em sedimentos dos rios, contaminando os peixes e causando um perigo potencial de exposição ao metil-mercúrio para toda a população.

A existência destes tipos de riscos à saúde evidencia a necessidade de metodologias que possam, ao menos, minimizar a exposição das pessoas ao mercúrio. Sendo assim, foi realizado um estudo que teve como objetivo principal avaliar uma metodologia educativa na qual adolescentes pudessem identificar e refletir criticamente sobre os riscos à saúde presentes no processo de extração do ouro.

Embora os fatores de risco dos ambientes de trabalho possam atingir à população como um todo, são os trabalhadores os afetados em maior intensidade por agentes etiológicos de doenças e acidentes, tais como, agentes químicos de variados graus de toxicidade, agentes físicos (ruído, radiações ionizantes e não ionizantes, desconforto térmico, alterações de pressão, descargas elétricas), agentes mecânicos, agentes ergonômicos, agentes biológicos e os agentes psicossociais. A exposição a estes agentes tem como conseqüências o aparecimento de acidentes do trabalho e doenças ocupacionais que alteram o quadro de mortalidade e morbidade dos trabal hadores (Câmara \& Corey, 1992; Faria et al., 1990; Frumkim \& Câmara, 1991; Mendes, 1980; Tambellini, 1978).

Entre os ambientes de trabal ho que podem ser classificados como altamente perigosos destaca-se a produção de ouro em garimpos. Nos últimos 20 anos a extração deste metal cresceu marcadamente no Brasil. Félix (1987) cita um crescimento de 9,6 toneladas em 1972 para 80,1 toneladas em 1986. Já para o ano de 1988 , Hasse (1993) estimou um total de 218,6 toneladas de ouro produzidas.

O aumento da produção do ouro pode estar associado a alterações do quadro sanitário nas áreas de garimpo e, entre os diversos fatores de risco resultantes deste tipo de atividade econômica, destaca-se o uso indiscriminado do mercúrio. O fato de o ouro ser encontrado sob a forma de pó exige o uso do mercúrio para for- mar um amál gama que facilita a identificação do ouro, geralmente na proporção 1:1, ou seja, para cada quilo de ouro, utiliza-se, em média, outro quilo de mercúrio, podendo esta proporção variar de 0,8 até 1,3 (Pffeiffer, 1988; Couto et al., 1988; Ferreira \& Appel, 1990).

A produção de ouro em garimpos pode ser classificada em três tipos: balsas, onde o material aurífero encontra-se nos sedimentos dos rios; veio, sendo o ouro localizado nas rochas; e baixão, nas margens de pequenos rios. Silva (1993) agrupa estes tipos de garimpos em primários (veio) e secundários (baixão e dragas ou balsas).

Utilizando-se o garimpo de baixão como modelo, pode-se dividir o processo de trabalho em quatro etapas (Couto, 1991), que são: a) preparo da infra-estrutura; b) desmonte hidráulico (moto-bomba que joga água sob forte pressão hidráulica para desmontar o barranco de cascalho); c) concentração do ouro, onde ao material condensado é adicionado o mercúrio metálico; d) queima do ouro, realizada através da queima do material amalgamado em uma batéia, restando o ouro e sendo o mercúrio metálico lançado na atmosfera.

A exposição do trabal hador ao mercúrio e a contaminação do meio ambiente ocorrem principalmente quando aquele adiciona mercúrio ao concentrado e na queima do ouro (maior risco de exposição). Após a etapa final de produção, o ouro é vendido em lojas especial izadas que re-queimam este metal. Este procedimento pode causar contaminação atmosférica urbana por concentrações residuais de mercúrio metálico (Malm et al., 1991; Tobar et al., 1990).

Existem equipamentos chamados "retortas", que queimam o amálgama ouro-mercúrio em circuito fechado, diminuindo o risco da exposição atmosférica dos trabalhadores por este metal (Pffeiffer, 1993). Todavia, os garimpeiros não costumam utilizar este equipamento, porque, segundo eles, a retorta pode reter quantidades de ouro e o preço do mercúrio é muito baixo, não compensando o seu reaproveitamento (Câmara \& Corey, 1992).

O mercúrio é um metal de elevada toxicidade. Penetra no organismo através de diferentes vias, dependendo de sua forma de apresentação. No caso dos garimpos, a forma metálica é absorvida, principalmente, pela via respiratória, após a queima do amál gama, e seu monitoramento ambiental deve ser feito através de amostras de ar (Câmara, 1993). No caso do metil-mercúrio, sua penetração ocorre pela via digestiva e o monitoramento ambiental é feito através de amostras da biota (peixes). Após pe- 
netrar no organismo, atinge a corrente sanguínea onde permanece durante um tempo (meia vida) que também depende da forma de apresentação. Depois, parte do mercúrio é depositada em tecidos, onde se conjuga com grupamentos sulfridrilas de proteínas (Galvão \& Corey, 1987), ou então é eliminado através da urina (principalmente forma metálica), cabelo (metil-mercúrio), suor, fezes, saliva e até leite materno (Clarkson et al., 1988).

Os efeitos do mercúrio no organismo variam também de acordo com a sua forma de apresentação. O mercúrio metálico pode causar intoxi cação aguda, onde predominam os sinais e sintomas respiratórios (ATSDR, 1989; WHO, 1991) e intoxicações subagudas e crônicas, onde aparecem os efeitos no sistema nervoso, rins e pele. No caso dos compostos orgânicos do mercúrio, destacam-se os seus efeitos crônicos, principalmente a nível do sistema nervoso e a possibilidade de lesão teratogênica (WHO, 1990).

É difícil precisar o número de pessoas expostas aos riscos originários da produção de ouro. Pode-se afirmar que estão expostos ao mercúrio metálico os trabalhadores que queimam ouro, trabalhadores próximos às áreas de queima, população geral próxima aos locais de queima no garimpo e nas lojas de compra de ouro (Gonçalves, 1993; Tobar et al., 1991). Quanto ao risco potencial de expostos ao metil-mercúrio, Hacon (1990), analisando resultados de vários pesquisadores brasileiros como Malm et al. (1990), sugeriu a possibilidade de estar ocorrendo metilação em rios de pequeno porte na Amazônia.

O número de garimpeiros no Brasil é praticamente impossível de ser avaliado com precisão. Um levantamento realizado pelo Departamento Nacional de Produção Mineral estimou um total de 300 mil trabalhadores concentrados principalmente no Estado do Pará. O número de garimpeiros é diretamente proporcional ao nível de produção do ouro, que por sua vez depende do preço nos mercados nacionais e internacionais. Não existem estatísticas confiáveis sobre a distribuição por faixa etária. Pode-se afirmar, porém, que os adolescentes, juntamente com os adultos jovens, são um grupo etário de elevada freqüência nos garimpos.

A questão relativa ao trabalho do adolescente no Brasil tem sido um tema ainda pouco discutido, talvez por ser um grupo que não esteja inserido no grupo materno-infantil, nem do trabalhador adulto. Contudo, é um grupo de al to risco porque está em fase de desenvolvimento físico e psíquico e também prioritário para implantações de atividades preventivas na área de saúde e trabal ho. Os adolescentes estão no início de suas vidas produtivas, ou ainda não ingressaram no mercado de trabalho.

Desde o período da Revolução Industrial, na Inglaterra, o trabalho da criança, do adolescente e da mulher, foi utilizado com um valor menor. Mendes (1980), em uma análise histórica deste período, cita que os donos das fábricas compravam o trabalho das crianças pobres nos orfanatos; mais tarde, como os salários dos pais operários não eram suficientes para manter a família, também os seus filhos foram obrigados a trabalhar nas fábricas e minas. Hoje, no Brasil, muitas são as crianças e adolescentes que ingressam no mercado de trabalho, a despeito do que determinou a Constituição Federal de 1988, em condições subumanas (Pinheiro et al., 1993).

Todos estes argumentos citados reforçam o objetivo principal deste estudo, que foi: identificar adolescentes garimpeiros e promover a discussão das relações entre saúde e trabalho através de uma metodologia educativa de informação e reflexão crítica. Outros objetivos mais específicos incluiam:

- Orientar os adolescentes sobre os riscos aos quais estavam submetidos nos seus ambientes de trabalho, de forma a contribuir na disseminação do conhecimento sobre saúde e prevenção;

- informar sobre o que compete ao trabalhador adolescente, a nível individual e coletivo, na busca da melhoria das suas condições de trabalho;

- promover o treinamento de recursos humanos (professores da escola, profissionais da Secretaria de Estado de Saúde e alunos da UFRJ ) na identificação, prevenção e controle de riscos à saúde dos adolescentes causados pelo ambiente de trabalho na produção de ouro.

\section{Materiais e métodos}

Esta metodologia já tinha si do testada por esta equipe com sucesso em adolescentes escolares de três áreas de diferentes níveis sócio-econômicos. A primeira experiência foi em uma escola de uma comunidade de baixa renda da antiga Favela da Maré, na Área de Planejamento 3.1 do Município do Rio de Janeiro. A segunda, em duas escolas, sendo uma urbana e a outra rural, no Município de Teresópolis, Rio de Janeiro. A última, ocorreu no Colégio Aplicação da Universidade Federal do Rio de Janeiro (FiIhote et al., 1993).

A escolha do Distrito de Monsenhor Horta, Município de Mariana, Minas Gerais, como Io- 
cal do estudo, deu-se porque a mineração de ouro constitui-se na principal atividade econômica deste Distrito, envolvendo em seu processo de produção pessoas de diversas faixas etárias, incluindo principalmente os adolescentes. Estes últimos participam, na maioria das vezes, como contratados temporários pelos donos dos garimpos ou em trabalho conjunto com pessoas da família. Além disso, foi também levado em consideração o fato de a Secretaria de Estado de Saúde de Minas Gerais (SESMG) estar iniciando um estudo sobre os efeitos da exposição ao mercúrio na saúde dos garimpeiros.

O Distrito de Monsenhor Horta surgiu há mais de 300 anos com a descoberta do ouro e fica situado a cerca de $20 \mathrm{Km}$ da sede do Município. Não foi possível estimar o número de adolescentes e a informação demográfica disponível era sobre o número total de habitantes: aproximadamente 2.000 pessoas (IBGE, 1993). O Município não conta com rede de esgotos, sendo abastecido por água não tratada. Suas atividades produtivas são basicamente agrícolas e de mineração de ouro.

Após o primeiro contato com uma das lideranças comunitárias de Monsenhor Horta, foi escolhida como local para desenvolvimento do programa a Escola Estadual Cônego Braga (única escola onde estudavam os adolescentes do Distrito de Monsenhor Horta). Foram também apresentados e discutidos os objetivos do projeto com a Diretora e os professores e definidos o número de alunos por turma e os horários de desenvolvimento do projeto.

A metodologia educativa foi planejada e executada em cinco fases, entre os dias 4 e 9 de abril, conforme explicitado abaixo:

Primeira Fase

Apresentação da equipe; discussão de toda a metodologia a ser empregada; aplicação de um questionário com perguntas simples e diretas que caracterizavam o perfil ocupacional dos adolescentes e que apresentavam situações de vida e trabalho para serem relacionadas com acidentes e doenças do trabalho; e apresentação de diapositivos mostrando pessoas trabalhando em garimpos, serviços domésticos, agropecuária, meios de transporte e outras atividades familiares à população do Distrito de Monsenhor Horta. Em seguida, foi discutida a relação destas ocupações com a saúde da população e os conceitos de acidentes e doenças do trabalho.

Segunda Fase

Discussão sobre as repercussões na saúde relacionadas com as profissões escolhidas, assim como as dos pais e parentes próximos.

Terceira Fase

Planejamento das atividades do quarto dia, cabendo aos adolescentes decidirem sobre as estratégias para abordar o tema saúde e trabaIho.

\section{Quarta Fase}

Desenvolvimento das atividades propostas na terceira fase. Os adolescentes decidiram realizar entrevistas filmadas (vídeo) com um dono de garimpo, duas professoras, uma família de carvoeiros, um jogador de futebol e uma aposentada. Também foram elaborados cartazes e realizadas dramatizações sobre o tema saúde e trabalho.

\section{Quinta Fase}

Avaliação qualitativa final dos adolescentes sobre o que apreenderam da relação entre saúde e trabalho, sendo aplicado novamente o questionário para avaliação quantitativa da metodologia e análise do vídeo produzido peIos alunos, onde estavam registradas todas as atividades desenvolvidas pelos adolescentes.

O questionário utilizado foi constituído de poucas perguntas para que sua aplicação fosse rápida e com conteúdo de fácil compreensão, incluindo os seguintes tipos de informações:

a) Identificação do adolescente: Data de nascimento, sexo, série que estudava e atividade ocupacional. Esta identificação não incluiu o nome do adolescente para evitar constrangimentos do aluno que não soubesse responder as perguntas.

b) Riscos relacionados ao trabalho: Doença prévia ou atual causada pelo trabalho, lesão (acidente) causada pelo trabalho, profissão que julgasse mais perigosa e especificação das doenças ou acidentes relacionados com esta ocupação.

Vale ressaltar que a utilização do mercúrio no garimpo é ilegal e entre os garimpeiros do Distrito de Monsenhor Horta existem até estratégias para divulgar a chegada de órgãos de fiscalização, notadamente o Instituto Brasileiro do Meio Ambiente e dos Recursos Naturais Renováveis (IBAMA). Este foi outro motivo pelo qual não foi solicitado o nome do adolescente e também optou-se por deixar que eles próprios relatassem a questão do uso do mercúrio. Não existiam referências a este metal no questionário, e sim, perguntas gerais sobre acidentes e doenças.

c) Caracterização do acidente de trabal ho atra- 
vés de quatro situações que incluíam a definição de acidente típico e acidente de trajeto, uma situação de acidente de trânsito a caminho do trabalho, uma doença causada pela ocupação e uma agressão dentro da empresa. Isto porque a legislação brasileira define acidente de trabal ho como toda ou qualquer lesão ou perturbação funcional que ocorra pelo exercício do trabalho, equiparando aos acidentes típicos, entre outros, o acidente no trajeto de casa para o trabal ho ou vice-versa, as doenças do trabalho e as agressões no local de trabalho.

A avaliação quantitativa da metodologia foi feita através da comparação entre as respostas corretas existentes no questionário an- tes e depois do desenvolvimento da atividade de campo. Os dados obtidos foram armazenados em microcomputador utilizando o programa EPIINFO (Dean et al., 1992). A análise estatística das diferenças entre as respostas nos questionários anterior e posterior foi feita utilizando os testes de Fisher e Qui-Quadrado.

\section{Resultados}

Todos os adolescentes residiam no Distrito de Monsenhor Horta e a sua distribuição por fase do programa educativo (anterior e posterior) segundo sexo e faixa etária está apresentada na

Tabela 1

Distribuição da população adolescente estudada por fase do programa, segundo sexo e faixa etária.

Monsenhor Horta, Mariana, MG - 1994.

\begin{tabular}{|c|c|c|c|c|c|c|c|}
\hline \multirow[t]{2}{*}{ Sexo } & \multirow[t]{2}{*}{ Idade } & \multicolumn{3}{|c|}{ Fase anterior } & \multicolumn{3}{|c|}{ Fase posterior } \\
\hline & & $\mathrm{n}$ & $\%$ por sexo & $\%$ pop. total & $\mathrm{n}$ & $\%$ por sexo & $\%$ pop. total \\
\hline \multirow[t]{3}{*}{ Sexo masculino } & $12-15$ & 11 & 37,9 & 15,7 & 13 & 48,1 & 19,1 \\
\hline & $16-19$ & 18 & 62,1 & 25,7 & 14 & 51,9 & 20,6 \\
\hline & Subtotal & 29 & 100,0 & 41,4 & 27 & 100,0 & 39,7 \\
\hline \multirow[t]{3}{*}{ Sexo feminino } & $12-15$ & 32 & 78,0 & 45,7 & 31 & 75,6 & 45,6 \\
\hline & $16-19$ & 9 & 22,0 & 12,9 & 10 & 24,4 & 14,7 \\
\hline & Subtotal & 41 & 100,0 & 58,6 & 41 & 100,0 & 60,3 \\
\hline \multirow[t]{2}{*}{ Ambos os sexos } & $12-15$ & 43 & 61,4 & 61,4 & 44 & 64,7 & 64,7 \\
\hline & $16-19$ & 27 & 38,6 & 38,6 & 24 & 35,3 & 35,3 \\
\hline Total & & 70 & 100,0 & 100,0 & 68 & 100,0 & 100,0 \\
\hline
\end{tabular}

Tabela 2

Escolaridade da população adolescente por sexo e fase do programa.

Monsenhor Horta, Mariana, MG - 1994.

\begin{tabular}{|c|c|c|c|c|c|}
\hline \multirow[t]{2}{*}{ Sexo } & \multirow[t]{2}{*}{ Série } & \multicolumn{2}{|c|}{ Fase anterior } & \multicolumn{2}{|c|}{ Fase posterior } \\
\hline & & $n$ & $\%$ & $n$ & $\%$ \\
\hline \multirow[t]{7}{*}{ Sexo masculino } & Até 4a Série & 3 & 10,3 & 3 & 11,1 \\
\hline & 5a Série & 8 & 27,6 & 10 & 37,0 \\
\hline & 6a Série & 4 & 13,8 & 4 & 14,8 \\
\hline & 7ạ Série & 4 & 13,8 & 4 & 14,8 \\
\hline & 8ạ Série & 6 & 20,7 & 6 & 22,2 \\
\hline & Sem Informação & 4 & 13,8 & - & - \\
\hline & Subtotal & 29 & 100,0 & 27 & 100,0 \\
\hline \multirow[t]{7}{*}{ Sexo feminino } & Até 4a Série & - & - & - & - \\
\hline & 5a Série & 12 & 29,3 & 13 & 31,7 \\
\hline & 6ạ Série & 17 & 41,5 & 17 & 41,5 \\
\hline & 7ạ Série & 4 & 9,7 & 6 & 14,6 \\
\hline & 8ạ Série & 4 & 9,7 & 4 & 9,8 \\
\hline & Sem Informação & 4 & 9,7 & 1 & 2,4 \\
\hline & Subtotal & 41 & 100,0 & 41 & 100,0 \\
\hline Total & & 70 & 100,0 & 68 & 100,0 \\
\hline
\end{tabular}


Tabela 1. Foram 70 alunos na fase anterior, sendo 41 (58,6\%) do sexo feminino e 29 (41,4\%) do sexo masculino. Na fase posterior responderam ao questionário 68 alunos, sendo 41 (60,3\%) do sexo feminino e 27 (39,7\%) do sexo masculino. Entre as meninas predominava o grupo etário entre 12 e 15 anos (respectivamente, 78\% e $75,6 \%$ nas fases anterior e posterior), enquanto entre os meninos houve o predomínio da faixa de 16 a 19 anos (respectivamente, 62,1\% e 51,9\% nas fases anterior e posterior).

Quanto à escolaridade (Tabela 2), a população masculina em ambas as fases teve a maioria dos alunos cursando a 5 a $(27,6 \%$ e $37 \%)$ e 8 a (20,7 e 22,2\%) séries. Já na população feminina, a maioria dos escolares cursava a 5a (29,3 e $31,7 \%$ ) e $6 a$ (41,5\% em ambas as fases) séries.

Na população masculina, nas duas fases, $100 \%$ dos adolescentes entre 16 e 19 anos trabaIhavam e, destes, 56\% relataram expecificamente o garimpo de ouro. Dos que se encontravam entre 12 e 15 anos, $84 \%$ trabalhavam, sendo $54 \%$ do total no garimpo. Além desta atividade econômica foram citadas atividades agropecuárias em geral. Na população feminina, o grupo etário entre 16 e 19 anos compreendeu a maior parte daquelas que trabalhavam (60\%), enquanto das que tinham entre 12 e 15 anos esta proporção alcançou $25 \%$. As adolescentes de ambas as faixas etárias que trabal havam eram empregadas domésticas. Por ser uma atividade ilegal e a equipe do projeto ter tido um contacto de apenas alguns dias com estes adolescentes, não pode ser desprezada a possibilidade de parte deles não terem citado o trabalho na atividade garimpeira e a exposição direta ao mercúrio.

Dos adolescentes que exerciam alguma atividade profissional, oito referiram já terem ficado doentes por causa do trabalho. Na fase posterior, talvez pelo maior conhecimento da definição de doença do trabalho, este número elevou-se para 11 alunos. Quanto às lesões características por acidentes, 21 afirmaram, em ambas as fases, já terem sofrido algum traumatismo no trabalho.

Na pergunta sobre qual a profissão era mais perigosa, as três mais citadas por fase foram, respectivamente: garimpeiro, policial e motorista, na fase anterior, e garimpeiro, bombeiro e motorista, na fase posterior. Quando foi solicitado que o adolescente indicasse uma doença ou acidente que viesse, por acaso, vitimar um trabalhador das profissões citadas como perigosas, a correta associação entre o tipo de ocupação e o risco a que o trabalhador poderia estar submetido sofreu um aumento expressivo da primeira para a segunda fase, passando de $40 \%$ para $70 \%$.
As Tabelas 3 a 6 oferecem uma avaliação comparativa dos índices de acertos dos adolescentes sobre os conceitos de acidentes de trabalho, antes e depois do desenvolvimento da metodologia.

A Tabela 3 apresenta as respostas corretas da definição de acidentes de trabalho por fase do programa educativo segundo sexo e faixa etária. Perguntou-se qual a definição de acidente de trabalho e foram apresentadas cinco opções de respostas. Observa-se que, para todos os adolescentes, apenas 27,1\% sabiam definir acidente de trabalho e ao final do projeto o índice de acerto alcançou cerca de 67,6\%. A análise através do Qui-Quadrado mostrou uma diferença significativa entre as fases. Este resultado ocorreu, com pequenas diferenças, para os dois sexos e em todas as faixas etárias. No sexo masculino o índice de acertos passou de $24,1 \%$ para $66,6 \%(p<0,01)$ e no sexo feminino de $29,3 \%$ para $68,3 \%$ ( $p<0,001)$. Quanto à faixa etária, os mesmos resultados foram obtidos para ambos os sexos e percebe-se que a população entre 12 e 15 anos obteve um melhor rendimento na assimilação correta da definição de acidente de trabalho.

A Tabela 4 apresenta respostas corretas da caracterização de acidentes de trajeto como acidentes de trabalho por fase do programa educativo. Foi perguntado se ocorreu um acidente de trabalho em uma situação hipotética em que um trabalhador sofre um traumatismo com fratura de uma perna quando se dirige ao trabalho. Nesta Tabela pode-se perceber que, tanto em relação ao sexo quanto à faixa etária, atingiu-se, praticamente, a totalidade das respostas corretas na fase posterior ( $p<0,001)$. Apenas um adolescente do sexo masculino não respondeu corretamente. Na fase anterior o índice de acerto alcançou 50\%, porém, deve-se ressaltar que havia apenas duas alternativas de resposta (sim ou não) e, por este motivo, esse resultado anterior era previsto.

$\mathrm{Na}$ Tabela 5 estão descritas as respostas corretas sobre a caracterização de doenças do trabalho por fase do programa educativo. O questionário apresentava uma situação em que um garimpeiro adquire uma gripe após uma chuva forte durante a sua jornada de trabalho. Na população masculina, independentemente da faixa etária, o índice de acerto na fase posterior foi de $100 \%$, com uma diferença significativa ( $p \varangle 0,001$ ) entre as duas fases $(58,6 \%$ para $100 \%)$. Pode-se notar que os adolescentes entre 16 e 19 anos se sobressaíram na caracterização correta das doenças do trabalho. Na população feminina não houve diferenças significativas entre as duas fases $(p>0,10)$, apresentan- 
do um acréscimo de 90,2 para 95,1\% no índice de acertos e até um pequeno decréscimo, para as meninas entre 16 e 19 anos (100\% para $90,0 \%)$.

$\mathrm{Na}$ análise da Tabela 6 destaca-se a diferença entre o índice de acertos sobre a caracterização das agressões nos locais de trabalho como acidentes de trabalho. Foi apresentada uma situação de briga entre dois trabalhadores em uma carpintaria. A diferença de acertos nas populações masculina e feminina entre as fases anterior e posterior foi a maior já observada. Comparando-se com os dados apresentados nas Tabelas anteriores, o item caracterização das agressões em locais de trabal ho foi o que exprimiu a maior assimilação. No total, enquanto apenas 8,5\% dos adolescentes faziam esta associação antes da metodologia, 77,9\% foi alcançado no final do programa ( $p \varangle 0,001$ ). $\mathrm{Na}$ população masculina a diferença entre as fases foi de $17,2 \%$ para $77,7 \%(p<0,001)$ e no sexo feminino de $2,4 \%$ para $78 \%(p \varangle 0,001)$.

Tabela 3

Definição correta de acidente de trabalho por fase do programa, segundo sexo e faixa etária.

Monsenhor Horta, Mariana, M G - 1994.

\begin{tabular}{|c|c|c|c|c|c|c|c|}
\hline \multirow[t]{3}{*}{ Sexo } & \multirow[t]{3}{*}{ Idade } & \multicolumn{3}{|c|}{ Fase anterior } & \multicolumn{3}{|c|}{ Fase posterior } \\
\hline & & \multirow{2}{*}{$\begin{array}{r}\text { Adolescentes } \\
\text { total }\end{array}$} & \multirow{2}{*}{$\begin{array}{r}\text { Respostas } \\
\text { corretas } \\
n\end{array}$} & \multirow{2}{*}{$\begin{array}{l}\text { Acertos } \\
\qquad \%\end{array}$} & \multirow{2}{*}{$\begin{array}{r}\text { Adolescentes } \\
\text { total }\end{array}$} & \multirow{2}{*}{$\begin{array}{r}\text { Respostas } \\
\text { corretas } \\
n\end{array}$} & \multirow{2}{*}{$\begin{array}{l}\text { Acertos } \\
\qquad \%\end{array}$} \\
\hline & & & & & & & \\
\hline \multirow[t]{3}{*}{ Sexo masculino } & $12-15$ & 11 & 1 & 9,1 & 13 & 8 & 61,5 \\
\hline & $16-19$ & 18 & 6 & 33,3 & 14 & 10 & 71,4 \\
\hline & Subtotal & 29 & 7 & 24,1 & 27 & 18 & 66,6 \\
\hline \multirow[t]{3}{*}{ Sexo feminino } & $12-15$ & 32 & 10 & 31,2 & 31 & 23 & 74,2 \\
\hline & $16-19$ & 9 & 2 & 22,2 & 10 & 5 & 50,0 \\
\hline & Subtotal & 41 & 12 & 29,3 & 41 & 28 & 68,3 \\
\hline \multirow[t]{2}{*}{ Ambos os sexos } & $12-15$ & 43 & 11 & 25,6 & 44 & 31 & 70,4 \\
\hline & $16-19$ & 27 & 8 & 29,6 & 24 & 15 & 62,5 \\
\hline \multicolumn{2}{|l|}{ Total } & 70 & 19 & 27,1 & 68 & 46 & 67,6 \\
\hline \multicolumn{8}{|c|}{$\begin{array}{l}\text { Total de adolescentes: } \chi^{2}=22,71 p<0,001 \\
\text { Adolescentes sexo masculino: } \chi^{2}=10,23 p<0,01 \\
\text { Adolescentes sexo feminino: } \chi^{2}=12,50 p<0,001\end{array}$} \\
\hline \multicolumn{8}{|l|}{ Tabela 4} \\
\hline
\end{tabular}

Caracterização de acidente de trajeto como acidente de trabalho por fase do programa, segundo sexo e faixa etária. Monsenhor Horta, Mariana, MG - 1994.

\begin{tabular}{|c|c|c|c|c|c|c|c|}
\hline \multirow[t]{3}{*}{ Sexo } & \multirow[t]{3}{*}{ Idade } & \multicolumn{3}{|c|}{ Fase anterior } & \multicolumn{3}{|c|}{ Fase posterior } \\
\hline & & \multirow{2}{*}{$\begin{array}{r}\text { Adolescentes } \\
\text { total }\end{array}$} & \multirow{2}{*}{$\begin{array}{r}\text { Respostas } \\
\text { corretas } \\
n\end{array}$} & \multirow{2}{*}{$\begin{array}{r}\text { Acertos } \\
\%\end{array}$} & \multirow{2}{*}{$\begin{array}{r}\text { Adolescentes } \\
\text { total }\end{array}$} & \multirow{2}{*}{$\begin{array}{r}\text { Respostas } \\
\text { corretas } \\
n\end{array}$} & \multirow{2}{*}{$\begin{array}{r}\text { Acertos } \\
\%\end{array}$} \\
\hline & & & & & & & \\
\hline \multirow[t]{3}{*}{ Sexo masculino } & $12-15$ & 11 & 5 & 45,4 & 13 & 13 & 100,0 \\
\hline & $16-19$ & 18 & 10 & 55,5 & 14 & 13 & 92,8 \\
\hline & Subtotal & 29 & 15 & 51,7 & 27 & 26 & 96,2 \\
\hline \multirow[t]{3}{*}{ Sexo feminino } & $12-15$ & 32 & 17 & 53,1 & 31 & 31 & 100,0 \\
\hline & $16-19$ & 9 & 4 & 44,4 & 10 & 10 & 100,0 \\
\hline & Subtotal & 41 & 21 & 51,2 & 41 & 41 & 100,0 \\
\hline \multirow[t]{2}{*}{ Ambos os sexos } & $12-15$ & 43 & 22 & 51,1 & 44 & 44 & 100,0 \\
\hline & $16-19$ & 27 & 14 & 51,8 & 24 & 23 & 95,8 \\
\hline Total & & 70 & 36 & 51,4 & 68 & 67 & 98,5 \\
\hline
\end{tabular}

Total de adolescentes: $\chi^{2}=40,42 p<0,001$

Adolescentes sexo masculino: $\chi^{2}=14,16 p<0,001$

Adolescentes sexo feminino: $\chi^{2}=26,45 p<0,001$ 


\section{Conclusões}

A análise estatística dos dados mostrando um elevado índice de assimilação dos conceitos de acidentes e doenças do trabalho depois de aplicada a metodologia coincidiu com a análise subjetiva favorável dos participantes da equipe. Esta análise levou em consideração o interesse e o nível de participação dos adolescentes, professores e das pessoas que moravam no Distrito.

Embora a metodologia, por uma questão estratégica que já foi explicada, enfatizasse conceitos gerais de saúde e trabalho, a questão dos garimpos de ouro e do uso do mercúrio apareceu durante todo o tempo e tornou-se o principal objeto de discussão. Isto contribuiu para que fossem reconhecidos os riscos da manipulação deste metal e discutidas al gumas propostas de prevenção e controle de seus efeitos. Além disso, mesmo para os que não trabal havam na produção de ouro, incluindo neste grupo principalmente o sexo feminino, esta experiência pode ser considerada como altamente proveitosa, uma vez que existe a possibilidade de exposição indireta ao mercúrio se a pessoa estiver próxima dos locais de queima de ouro.

Tabela 5

Caracterização da doença do trabalho como acidente de trabalho por fase do programa, segundo sexo e faixa etária Monsenhor Horta, Mariana, MG - 1994.

\begin{tabular}{|c|c|c|c|c|c|c|c|}
\hline \multirow[t]{3}{*}{ Sexo } & \multirow[t]{3}{*}{ Idade } & \multicolumn{3}{|c|}{ Fase anterior } & \multicolumn{3}{|c|}{ Fase posterior } \\
\hline & & \multirow{2}{*}{$\begin{array}{r}\text { Adolescentes } \\
\text { total }\end{array}$} & \multirow{2}{*}{$\begin{array}{r}\text { Respostas } \\
\text { corretas } \\
n\end{array}$} & \multirow{2}{*}{$\begin{array}{l}\text { Acertos } \\
\qquad \%\end{array}$} & \multirow{2}{*}{$\begin{array}{r}\text { Adolescentes } \\
\text { total }\end{array}$} & \multirow{2}{*}{$\begin{array}{r}\text { Respostas } \\
\text { corretas } \\
n\end{array}$} & \multirow{2}{*}{$\begin{array}{l}\text { Acertos } \\
\qquad \%\end{array}$} \\
\hline & & & & & & & \\
\hline \multirow[t]{3}{*}{ Sexo masculino } & $12-15$ & 11 & 2 & 18,1 & 13 & 13 & 100,0 \\
\hline & $16-19$ & 18 & 15 & 83,3 & 14 & 14 & 100,0 \\
\hline & Subtotal & 29 & 17 & 58,6 & 27 & 27 & 100,0 \\
\hline \multirow[t]{3}{*}{ Sexo feminino } & $12-15$ & 32 & 28 & 87,5 & 31 & 30 & 96,7 \\
\hline & $16-19$ & 9 & 9 & 100,0 & 10 & 9 & 90,0 \\
\hline & Subtotal & 41 & 37 & 90,2 & 41 & 39 & 95,1 \\
\hline \multirow[t]{2}{*}{ Ambos os sexos } & $12-15$ & 43 & 30 & 69,7 & 44 & 43 & 97,7 \\
\hline & $16-19$ & 27 & 24 & 88,8 & 24 & 23 & 95,8 \\
\hline \multicolumn{2}{|l|}{ Total } & 70 & 54 & 77,1 & 68 & 66 & 97,0 \\
\hline \multicolumn{8}{|c|}{$\begin{array}{l}\text { Total de adolescentes: } \chi^{2}=12,06 p<0,001 \\
\text { Adolescentes sexo masculino: } \chi^{2}=14,22 p<0,001 \\
\text { Adolescentes sexo feminino: } \chi^{2}=0,72 p>0,10\end{array}$} \\
\hline \multicolumn{8}{|l|}{ Tabela 6} \\
\hline
\end{tabular}

Caracterização de agressões físicas como acidente de trabalho por fase do programa, segundo sexo e faixa etária. Monsenhor Horta, Mariana, MG - 1994.

\begin{tabular}{|c|c|c|c|c|c|c|c|}
\hline \multirow[t]{3}{*}{ Sexo } & \multirow[t]{3}{*}{ Idade } & \multicolumn{3}{|c|}{ Fase anterior } & \multicolumn{3}{|c|}{ Fase posterior } \\
\hline & & \multirow{2}{*}{$\begin{array}{r}\text { Adolescentes } \\
\text { total }\end{array}$} & \multirow{2}{*}{$\begin{array}{r}\text { Respostas } \\
\text { corretas } \\
n\end{array}$} & \multirow{2}{*}{$\begin{array}{r}\text { Acertos } \\
\%\end{array}$} & \multirow{2}{*}{$\begin{array}{r}\text { Adolescentes } \\
\text { total }\end{array}$} & \multirow{2}{*}{$\begin{array}{r}\text { Respostas } \\
\text { corretas } \\
n\end{array}$} & \multirow{2}{*}{$\begin{array}{r}\text { Acertos } \\
\%\end{array}$} \\
\hline & & & & & & & \\
\hline \multirow[t]{3}{*}{ Sexo masculino } & $12-15$ & 11 & 1 & 9,0 & 13 & 10 & 76,9 \\
\hline & $16-19$ & 18 & 4 & 22,2 & 14 & 11 & 78,5 \\
\hline & Subtotal & 29 & 5 & 17,2 & 27 & 21 & 77,7 \\
\hline \multirow[t]{3}{*}{ Sexo feminino } & $12-15$ & 32 & 1 & 3,1 & 31 & 25 & 80,6 \\
\hline & $16-19$ & 9 & 0 & 0,0 & 10 & 7 & 70,0 \\
\hline & Subtotal & 41 & 1 & 2,4 & 41 & 32 & 78,0 \\
\hline \multirow[t]{2}{*}{ Ambos os sexos } & $12-15$ & 43 & 2 & 4,6 & 44 & 35 & 79,5 \\
\hline & $16-19$ & 27 & 4 & 14,8 & 24 & 18 & 75,0 \\
\hline Total & & 70 & 6 & 8,5 & 68 & 53 & 77,9 \\
\hline
\end{tabular}

Total de adolescentes: $\chi^{2}=67,82 p<0,001$

Adolescentes sexo masculino: $\chi^{2}=20,60 p<0,001$

Adolescentes sexo feminino: $\chi^{2}=48,73 p<0,001$ 
A discussão de todos os itens do questionário mostrou claramente que os objetivos do estudo foram alcançados. Torna-se desnecessário repetir todas as diferenças significativas entre as respostas corretas antes e depois da aplicação da metodologia pelos adolescentes de ambos os sexos. A única excessão foi a caracterização da doença do trabalho (Tabela 5) para o sexo feminino.

Este estudo deve ser consi derado ainda como um projeto piloto e o seu desenvolvimento deve ser recomendado com reservas para áreas garimpeiras dos Estados que compõem a Amazônia Legal. O Distrito de Monsenhor Horta apresenta características sociais e econômicas que diferem da Região Amazônica. Além disso,

\section{Agradecimentos}

Os autores agradecem à Dra. Leilane Coelho Amorim, à Dra. Dirce Carvalho Amaral e ao Dr. Walbery Roque de Sá, todos da Secretaria de Estado de Saúde de Minas Gerais; à Profa. Maria Angélica Fernandes, liderança comunitária local; à Profa. Maria Raimunda Alves (então Diretora) e a toda equipe de professores da Escola Estadual Cônego Braga; à Profa. Elizabeth Costa Dias do Depto de Medicina Preventiva da UFM G e aos adolescentes de Monsenhor Horta. os seus índices de violência são insignificantes e não existem relatos de casos de malária. Estes eventos, de alta freqüência na Amazônia, poderiam centralizar as discussões, minimizando as questões de saúde relacionadas com o uso do mercúrio.

Como avaliação final pode-se dizer que, para as áreas garimpeiras do Estado de Minas Gerais, o uso desta metodologia educativa deve ser incentivado. A participação efetiva da Coordenadoria de Saúde do Trabalhador da Secretaria de Estado de Saúde de Minas Gerais (SESMG) no desenvolvimento do projeto pode ter contribuído para que este trabalho tenha desdobramentos em outras áreas do Estado.

\section{Referências}

ATSDR (Agency for Toxic Substances and Disease Registry), 1989. Toxicological Profile for Mercury. Atlanta: Public Health Service.

BRASIL, 1988. Constituição da República Federativa do Brasil. Rio de Janeiro: Fundação Universitária José Bonifácio.

CÂMARA, V. de M. \& COREY, G., 1992. Epidemiologia e Meio Ambiente: o Caso dos Garimpos de Ouro no Brasil. Metepec: Centro Panamericano de Ecologia Humana e Saúde (ECO/OPS).

CÂM ARA, V. de M., 1993. Mercúrio em Áreas de Garimpos de Ouro. Série Vigilância 12. Metepec: Centro Panamericano de Ecologia Humana e Saúde (ECO/OPS).

CLARKSON, T. W.; FRIBERG, L.; NORDBERG, G. F. \& SAGER, P., 1988. Biological Monitoring of Metals. New York: Plenum Press.

COUTO, R. C. de S.; CÂM ARA, V. de M. \& SABROSA, P. C., 1988. Intoxicação mercurial: resultados preliminares em duas áreas garimpeiras-PA, Brasil. Cadernos de SaúdePública, 4:301-315.

COUTO, R. C. de S., 1991. Buscando o Ouro-Perdendo Saúde: Um Estudo Sobre as Condi ções de Saúde no Garimpo do Cumaru. Tese de Mestrado, Rio de Janeiro: Escola Nacional de Saúde Pública/ Fiocruz.

DEAN, A. G.; DEAN, J. A.; BURTON, A. H. \& DICKER, R. C., 1992. Epi Info, Versión 5. A Word Processing, Database and Statistics System for Epidemiology with Microcomputers. Atlanta: Center for Diseases Control and World Health Organization.

FARIA, M. M.; POSSAS, C. A.; DIAS, E. C.; MENDES, R.; CÂM ARA, V. \& MELRO, A., 1990. SaúdeeTrabalho: Desafios Para uma Política. Rio de Janeiro: Abrasco.

FÉLIX, J. T. 1987. Análise da produção de ouro no Brasil. Brasil Mineral, 48:90-96.

FERREIRA, R. H. \& APPEL, L. E., 1990. Mercúrio: fontes e usos. Resumos Técnicos do Projeto Desenvolvimento de Tecnologia Ambiental no Garimpo de Ouro de Poconé. Rio de Janeiro: Centro de Tecnologia Mineral/CNPq. 
FILHOTE, M. I. de F.; LIMA, M. I. M. \& CÂMARA, V. de M., 1993. Avaliação de uma metodologia para programas de saúde do trabalhador para adolescentes. Anais da 45a Reunião Anual da SBPC. Sociedade Brasileira para o Progresso da Ciência, Recife, Brasil, p.365.

FRUM KIM, H. \& CÂMARA, V. de M., 1991. Occupational health and safety in Brazil. American Journal of Public Health, 81:1619-1624.

GALVÃO, L. A. C. \& COREY, G., 1987. Mercurio. Metepec: Centro Panamericano de Ecología Humana y Salud (ECO/OPS).

GONÇALVES, A. 1993. Saúde, garimpagem e mercúrio entre os Kayapó-Gorotire. In: Conseqüências da Garimpagem no Âmbito Social e Ambiental da Amazônia (A. Mathis \& R. Rehaag, eds.), pp.61-63. Belém: Fase, Buntistift e Katalyse.

HACON, S., 1990. Contaminação por Mercúrio na Amazônia. Documento elaborado para o Ministério da Saúde e a Organização Pan-Americana da Saúde, Brasília. (mimeo.)

HASSE, R. F., 1993. A comercialização de mercúrio no Brasil. In: Conseqüências da Garimpagem no Âmbito Social eambiental da Amazônia (Mathis A. \& Rehaag R., eds.), pp.77-94. Belém: Fase, Buntistift e Katalyse.

IBGE (Fundação Instituto Brasileiro de Geografia e Estatística), 1993. Sinopse Preliminar do Censo Demográfico de 1991. Cuiabá: IBGE.

MALM, O; PFEIFFER, W. C.; BASTOS, W. R. \& SOUZA, C. M. M., 1990. Mercury pollution due to gold mining in the Madeira River basin, Brazil. Ambio 19:11-15.

MENDES, R., 1980. Medicina do Trabalho-Doenças profissionais. São Paulo: Sarvier.
PFEIFFER, W. C. \& LACERDA, D., 1988. Mercury inputs into the Amazon region, Brasil. Environmental and Technological Letters, 9:325-330.

PFEIFFER, W. C., 1993. O controle da poluição ao mercúrio nos garimpos de ouro. In: Mercúrio em Áreas de Garimpos de Ouro (Câmara V. de M., ed.), pp.129-126. Metepec: Centro Pan-Americano de Ecologia Humana e Saúde (ECO/OPS).

PINHEIRO, A. B.; PINHEIRO P.; CÂM ARA, V. de M. \& GARFIELT, V., 1993. Um retrato da violência: a infância e a adolescência em um serviço de emergência. Anais do II Congresso da RedeIDA/BRASIL. Rede IDA/BRASIL, São Paulo.

SILVA, A. P., 1993. As diversas formas de garimpos de ouro, suas emissões de mercúrio e mecanismos de dispersão nos diversos compartimentos ambientais. In: Conseqüências da Garimpagem no Âmbito Social e Ambiental da Amazônia (A. Mathis \& R. Rehaag, eds), pp.48-56. Belém: Fase, Buntistift e Katalyse.

TAM BELLINI, A. T., 1978. O trabalho e a doença. In: Saúde e Medicina no Brasil (R. Guimarães, ed.), pp. 93-129. Rio de Janeiro: Graal.

TOBAR, C.; HACON, S. \& CÂM ARA, V. de M., 1991. Município de Alta Floresta. Pré-Diagnóstico da Situação de Saúde da População e de Grupos Ocupacional mente Expostos. Rio de Janeiro: Centro de Estudos de Saúde do Trabal hador e Ecologia Humana/ Fiocruz.

WHO (World Health Organization). 1990. Methylmercury. Environmental Health Criteria 101. Geneva: WHO

WHO (World Health Organization). 1991. Inorganic Mercury. Environmental Health Criteria 118. Geneva: WHO. 